\title{
The Microstructure of Self-Healed PVA ECC Under Wet and Dry Cycles
}

\author{
Jia Huan Yu, ,*, Wei Chen ${ }^{\mathrm{a}}$, Ming Xin Yu, Yang En Hua \\ aschool of Civil Engineering, ShenYang Jianzhu University, \\ LiaoNing, 110168, People's Republic of China \\ ${ }^{\mathrm{b}}$ Department of Civil and Environmental Engineering, University of Michigan, \\ Ann Arbor, Michigan, 48105, United States of America
}

Received: December 15, 2009; Revised: March 9, 2010

\begin{abstract}
Self-healing of ECC (Engineered Cementitious Composites) subjected to cyclic wetting and drying regimes is investigated in this paper. ECC structures subjected to outdoor environmental conditions such as wind and rain runoff can be simulated by accelerated test method of wetting and drying cycles. Uniaxial tensile tests of ECC M45 and ECC 2.8FA specimen are conducted respectively. It is found that crack width of ECC 2.8FA is around $10 \mu \mathrm{m}$ with increased amount of fly ash, while the crack width of ECC M45 is around $100 \mu \mathrm{m}$. New insights about the microstructure and chemical composition analysis of ECC specimens initially cracked to $2 \%$ strain and then self-healed under wet-dry cycles are presented.
\end{abstract}

Keywords: ECC, self-healing, microstructure, fly ash

\section{Introduction}

PVA (Polyvinyl alcohol) ECC is an ultra-ductile PVA fiber reinforced cement based composite which has metal-like features when loaded in tension. Yu et al. ${ }^{1,2}$ proved that the uniaxial stressstrain curve showed a yield point followed by strain-hardening up to several percent of strain, resulting in a material ductility of at least two orders of magnitude higher than normal concrete or standard fiber reinforced concrete. ECC provides crack width to below $100 \mu \mathrm{m}$ even when deformed to several percent tensile strain during saturated multiple cracking. (Figure 1). As opposed to formation of a single localized crack in concrete, Yang ${ }^{3}$ and $\mathrm{Li}^{4}$ produced ECC with multiple saturated cracking phenomenon by generation of a large number of distributed matrix cracks bridged by fibers. However, the crack width of concrete is not self-controlled and is usually in the range of several hundred $\mu \mathrm{m}$ to several $\mathrm{mm}$. Consequently, multiple cracking permits the composite material to accommodate significant deformations while retaining a macroscopic integrity and small crack width.

ECC tensile strain hardening is a result of realizing and tailoring the synergistic interaction between fiber, matrix and interface. Micromechanics has been used as a tool to link material microstructures to ECC tensile strain hardening behavior. Desirable tensile strain capacity several hundred times that of normal concrete can be achieved by tailoring material microstructures once the established linkages are utilized in material component tailoring.

Yang et al. ${ }^{5}$ has shown that the long term ductility and durability of ECC after cracking can be improved by self-healing. The chemical make-up and physical properties, self-controlled tight crack width and high tensile ductility of ECC makes selfhealing prevails in a variety of environmental conditions even when the composite is deliberately damaged by tensioning to several percent strain. It is found that self-healing can take place automatically at cracked locations without external intervention.
The crack width distribution is one of the most important factors that have effect on the self-healing ability of ECC. Also chemical productions stemming from mix design and environmental conditions have great impacts on the self-healing property. It is shown by Edvardsen ${ }^{6}$ that self-healing originated from the carbonation of calcium in cement matrix. The precipitation of these carbonates is dependent on the $\mathrm{pH}$ value of the water and calcium ion concentration at the crack surface. The more calcium ions available, the more likely precipitates will form. Cyclic wetting and drying at controlled temperatures can be taken as accelerated test method to simulate outdoor environmental conditions. Therefore the effects of the environmental conditions on damaged ECC can be described via the model of water-penetrated crack (Figure 2). As water moves more slowly through cracks with smaller crack width, $\mathrm{pH}$ levels rise simultaneously with carbonate precipitation. In addition, the process is dependent on the amount of bicarbonate, which is the dissolution of carbon dioxide in the water.

The process of carbonation reaction is the following:

$$
\begin{aligned}
& \mathrm{Ca}_{2}^{+}+\mathrm{CO}_{3}^{2-} \Leftrightarrow \mathrm{CaCO}_{3}\left(\mathrm{PH}_{\text {water }}>8\right) \quad \text { (Equation 1) } \\
& \mathrm{Ca}_{2}^{+}+\mathrm{HCO}_{3}^{-} \Leftrightarrow \mathrm{CaCO}_{3}+\mathrm{H}^{+}\left(7.5<\mathrm{PH}_{\text {water }}<8\right)(\text { Equation 2) }
\end{aligned}
$$

As the water which contains $\mathrm{CO}_{2}$ penetrates the pores of hardened cement paste, it dissolves additional $\mathrm{Ca}^{2+}$ ions from the $\mathrm{Ca}(\mathrm{OH})_{2}$ and the $\mathrm{C}-\mathrm{S}-\mathrm{H}$. Thus the $\mathrm{pH}$ value of this water will rise. Meanwhile, the alkalis, $\mathrm{KOH}$ and $\mathrm{NaOH}$ effect a rise in the $\mathrm{pH}$ value $(\mathrm{pH}>8)$. Therefore the bicarbonates in the water can be converted into carbonates. As a result, the dissolved $\mathrm{Ca}^{2+}$ ions will diffuse into the flowing-through water and get removed by the water.

$\mathrm{Li}$ and Yang ${ }^{7}$ have performed mechanical and permeability tests on ECC to investigate the effects of multiple cracking on self-healing. 

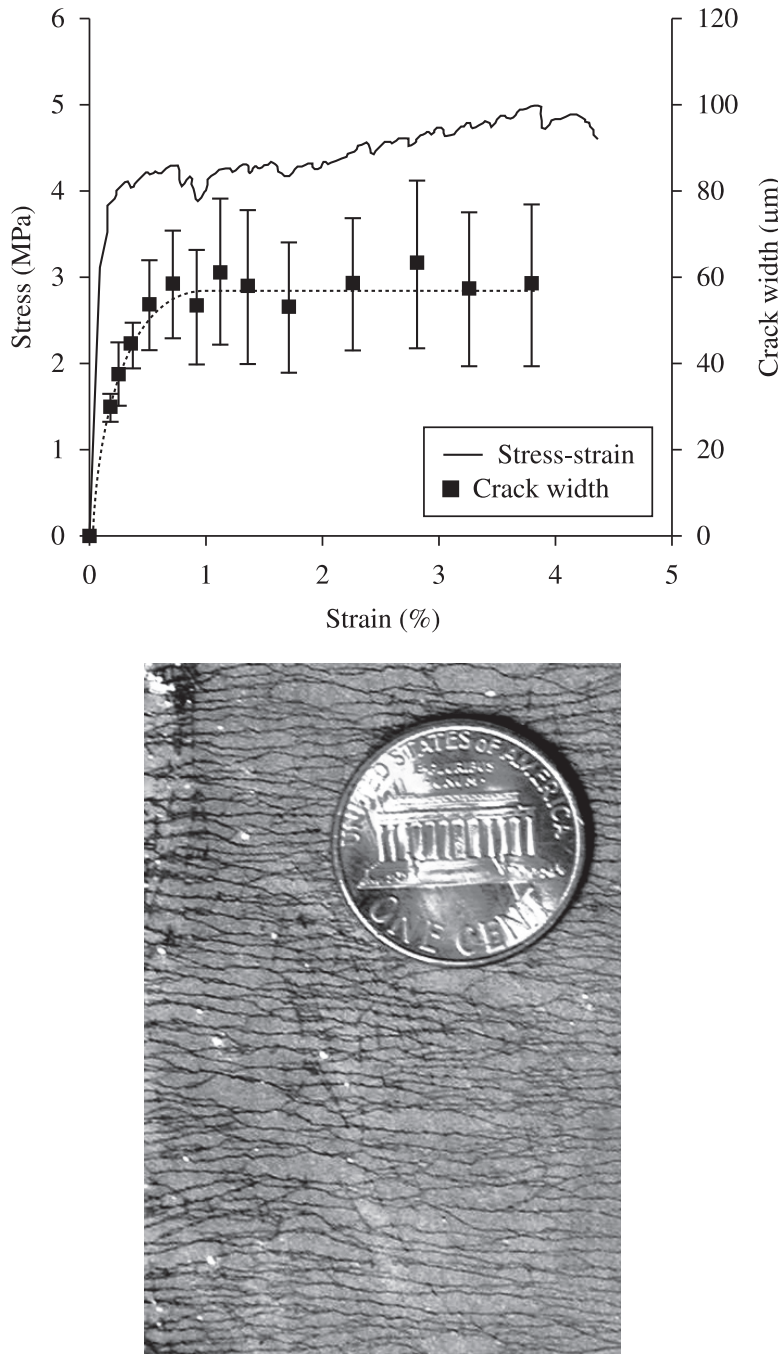

Figure 1. Typical stress-strain-crack width relationship and saturated crack pattern of PVA-ECC.

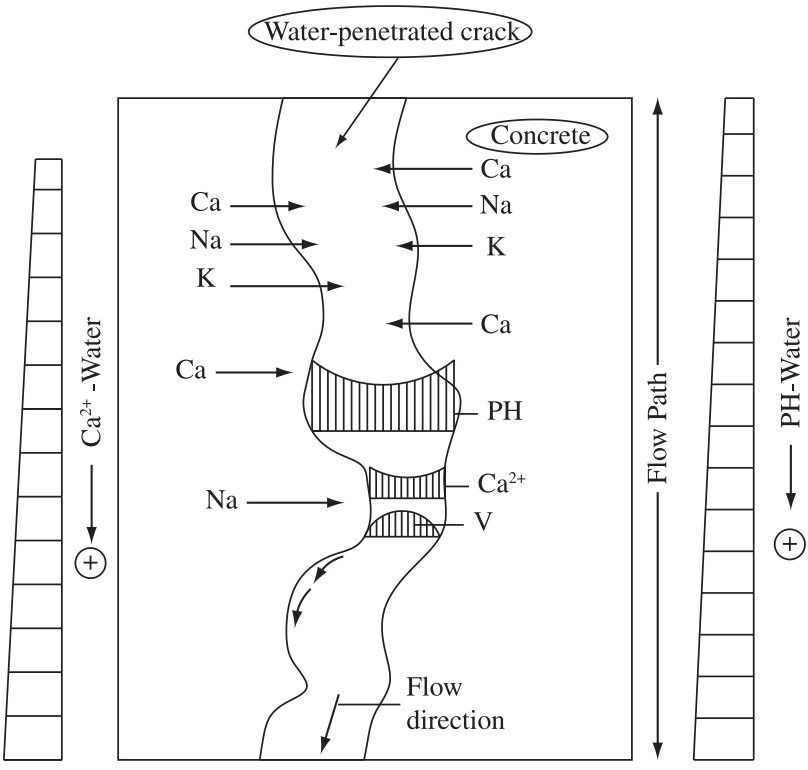

Figure 2. Water-penetrated crack of cementitious composite.

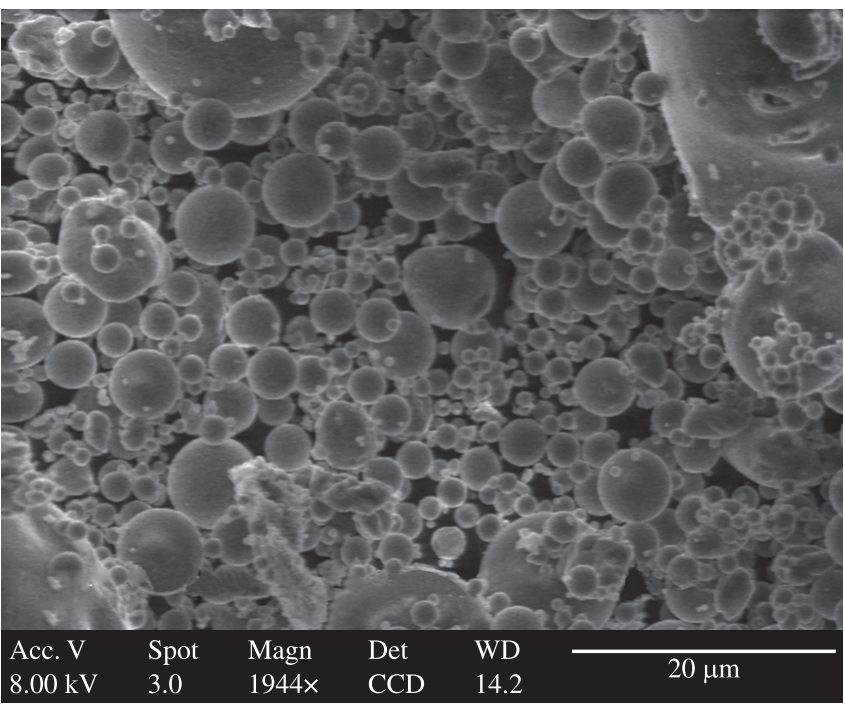

(a)

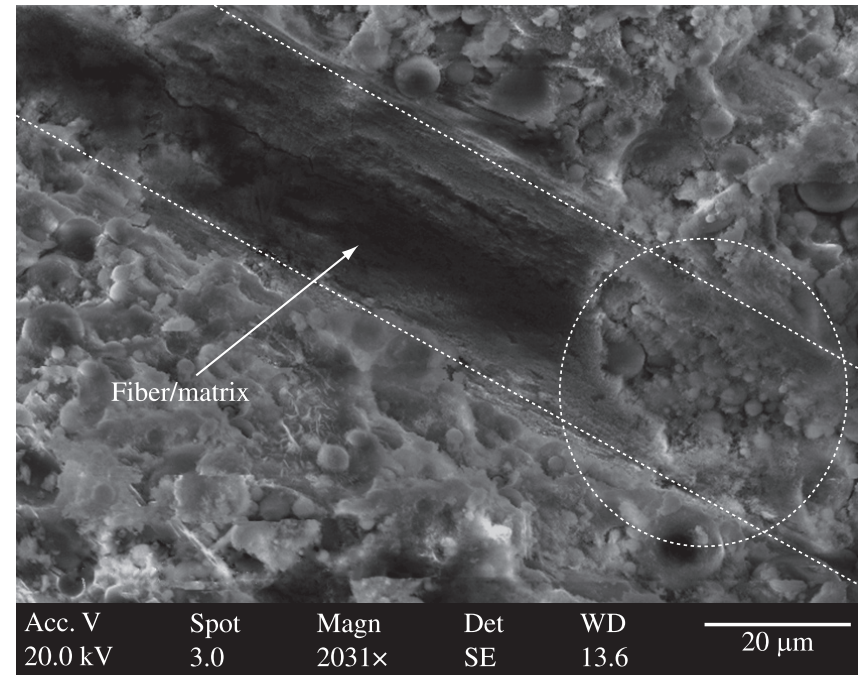

(b)

Figure 3. SEM photos of a) class F fly ash and b) Interface transition zone of ECC with fly ash.

Table 1. Composition of ECC M45 and 2.8FA.

\begin{tabular}{cccccc}
\hline Component $(\mathrm{g})$ & Cement & Sand & Fly Ash & Water & PVA Fiber \\
\hline ECC M45 & 3424 & 2739 & 4190 & 1991 & 156 \\
ECC 2.8FA & 1941 & 2737 & 5436 & 1925 & 156 \\
\hline
\end{tabular}

Table 2. Property of PVA fiber.

\begin{tabular}{ccccc}
\hline Material & $\begin{array}{c}\text { Length } \\
(\mathrm{mm})\end{array}$ & $\begin{array}{c}\text { Diameter } \\
(\mu \mathrm{m})\end{array}$ & $\begin{array}{c}\text { Tensile Strength } \\
(\mathrm{MPa})\end{array}$ & $\begin{array}{c}\text { Tensile Modulus } \\
(\mathrm{GPa})\end{array}$ \\
\hline PVA & 12 & 40 & 1600 & 40 \\
\hline
\end{tabular}

It was found that a maximum crack width below $50 \mu \mathrm{m}$ show complete recovery and above $150 \mu \mathrm{m}$ shows partial recovery. In this paper, a systematic investigation to understand the effects of crack width and material properties on self-healing of ECC is performed. The influence of fly ash on self-healing is investigated by two mix designs, ECC M45 and ECC 2.8FA. EDX (Energy Dispersive X-ray Spectroscopy) 


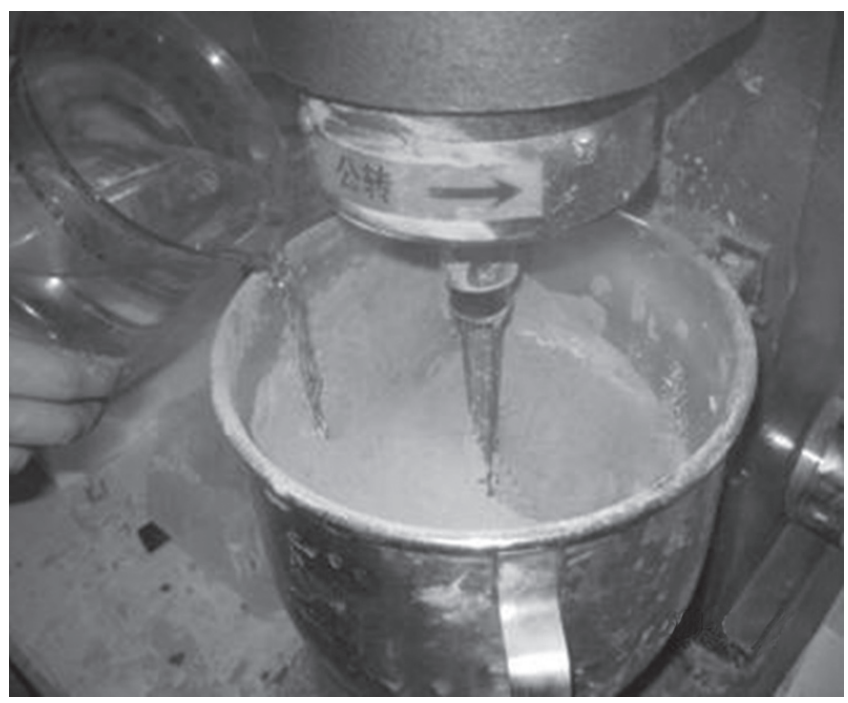

(a)

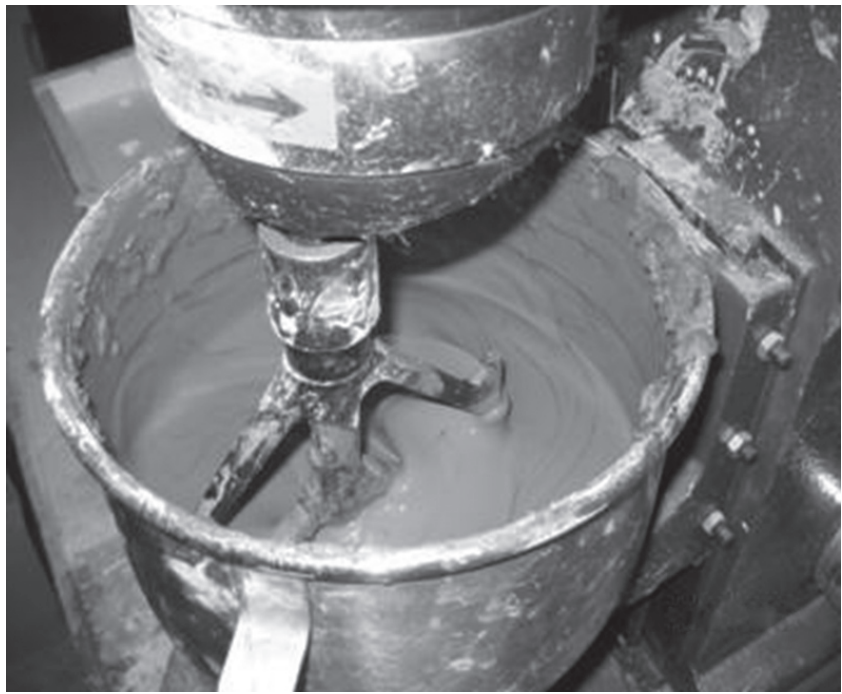

(c)

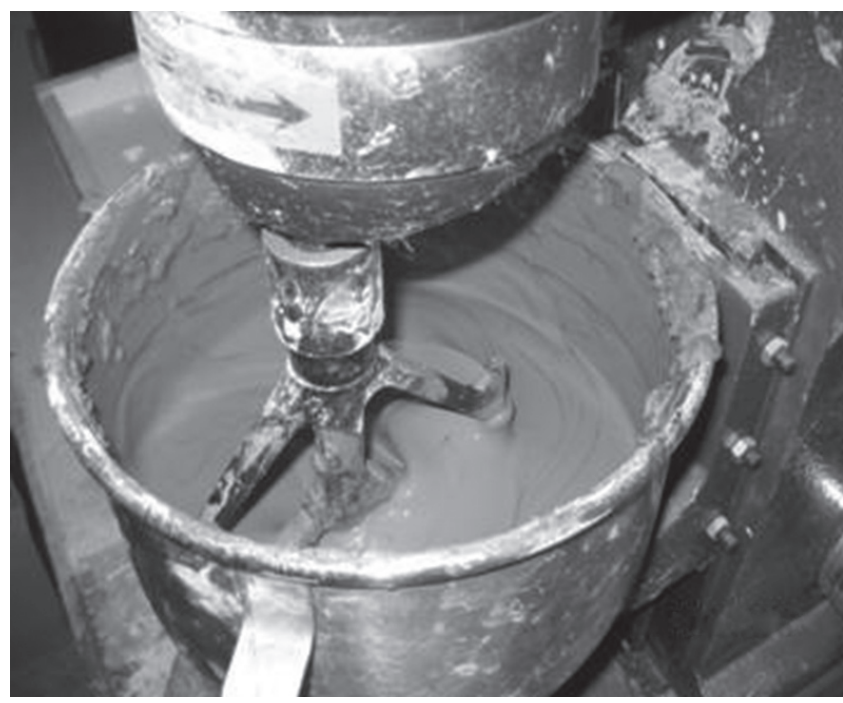

(b)

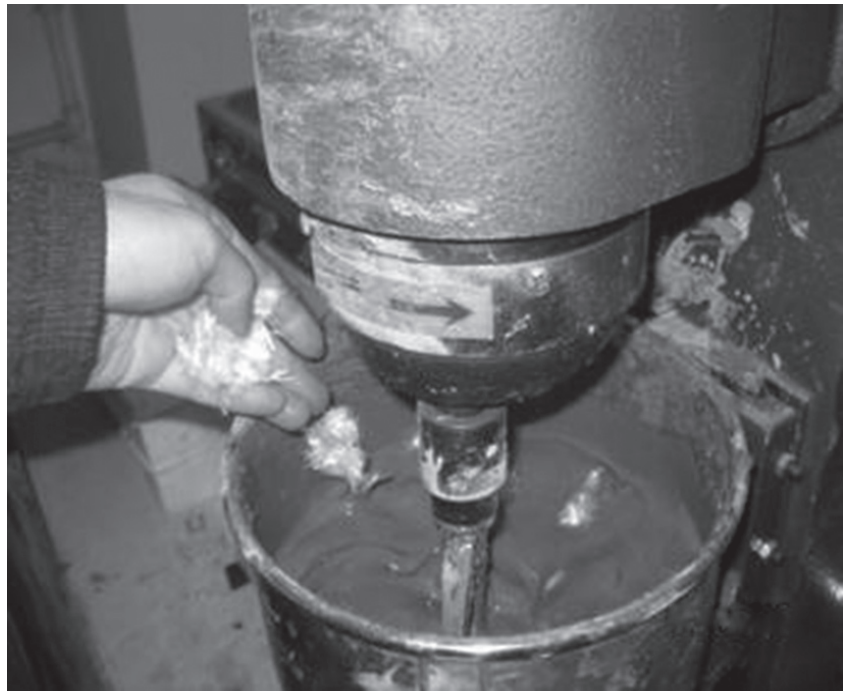

(d)

Figure 4. Mixing process of ECC: a) adding water; b) adding super-plasticizer; c) mixture without fiber; and d) adding fiber.

analysis is also carried out in order to confirm the composition of chemical products necessary for self-healing.

\section{Experimental Program}

\subsection{Materials}

In this research, the PVA ECC mixture consists of cement, sand, fly ash, fiber and superplasticizer. The mix proportions for ECC M45 and ECC 2.8FA with Flyash/Cement $(\mathrm{FA} / \mathrm{CM})=2.8$ are listed in Table 1 and the unit adopted for composition is gram. Proportioning of each component with the correct mechanical and geometric properties is necessary to attain the unique ductile behaviour. Coarse aggregates are not used as they tend to increase fracture toughness which adversely affects the unique ductile behaviour of the composite. The cement used is Type I Portland ${ }^{\circledR}$ Cement from Holcim Cement Co., MI, USA. The water reducing agent used as superplasticizer (SP) is ADVA Cast 530 from W. R. Grace \& Co., IL, USA. Discontinuous polymer fiber, K-II REC ${ }^{\mathrm{TM}}$

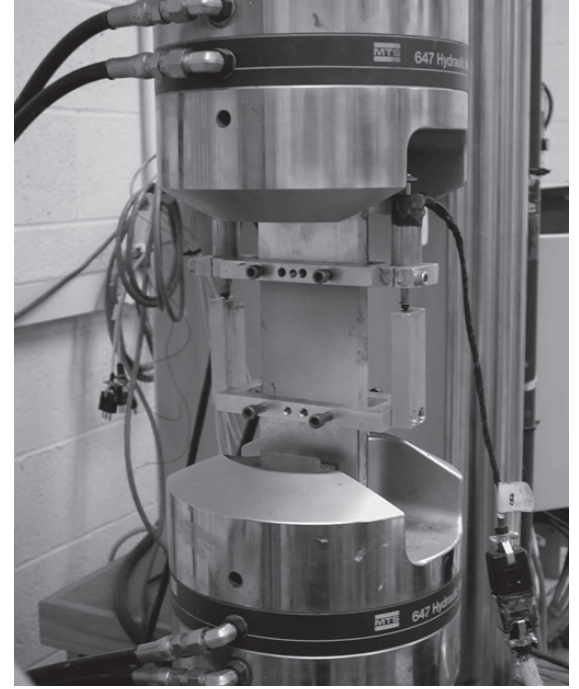

Figure 5. Uniaxial tensile test setup. 
polyvinyl alcohol (PVA) fiber through Kuraray Co. Ltd of Osaka, Japan is used at $2 \%$ volume fraction. The dimensions of the hydrophilic PVA fiber are $8 \mathrm{~mm}$ in length and $39 \mu \mathrm{m}$ in diameter on average. The nominal tensile strength of the fiber is $1600 \mathrm{MPa}$ and the density of the fiber is $1300 \mathrm{~kg} \cdot \mathrm{m}^{-3}$. The fiber is surfacecoated by oil ( $1.2 \%$ by weight) in order to reduce the fiber/matrix interfacial bond strength. The properties of the PVA fiber is given in Table 2. Pozzolanic admixture used is a low calcium Class F fly ash from Boral, TX, USA. Silica sand with a size distribution from 50 to $250 \mu \mathrm{m}$ is used as fine aggregate.

The choice of class F fly ash in ECC is due to its abundant availability (practical consideration) and less energy-intensity (i.e. less post-processing) when compared with bottom ash and fine fly ash. Micromechanics analysis also indicated that the increase of fiber/matrix interface frictional bond in ECCs utilizing fly ash is responsible for the more tight crack width and more saturated multiple cracking (Figure 3). This is mainly attributed to the secondary hydration that fly ash can provide, and therefore resulting in a denser matrix.

\subsection{Mixing and curing}

Appropriate weight and adding sequence of the constituent must be determined because very little difference results in considerable change of the property of acquired PVA ECC mixture. The sand and cement were mixed dryly first approximately for 30 - 60 seconds until the mixture became homogeneous (Figure 4a). Various chemical admixtures were applied to control the rheological properties of fresh matrix (Figure 4b), including melamine formaldehyde sulfate as superplasticizer (SP) and hydroxypropylmethyl cellulose (HPMC) with molecular weight

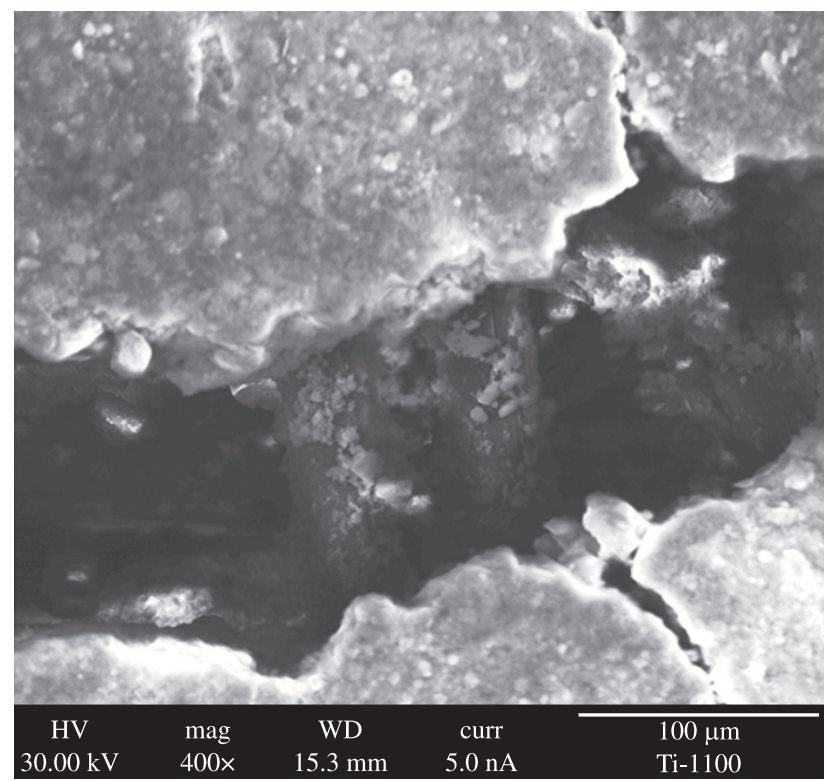

(a)

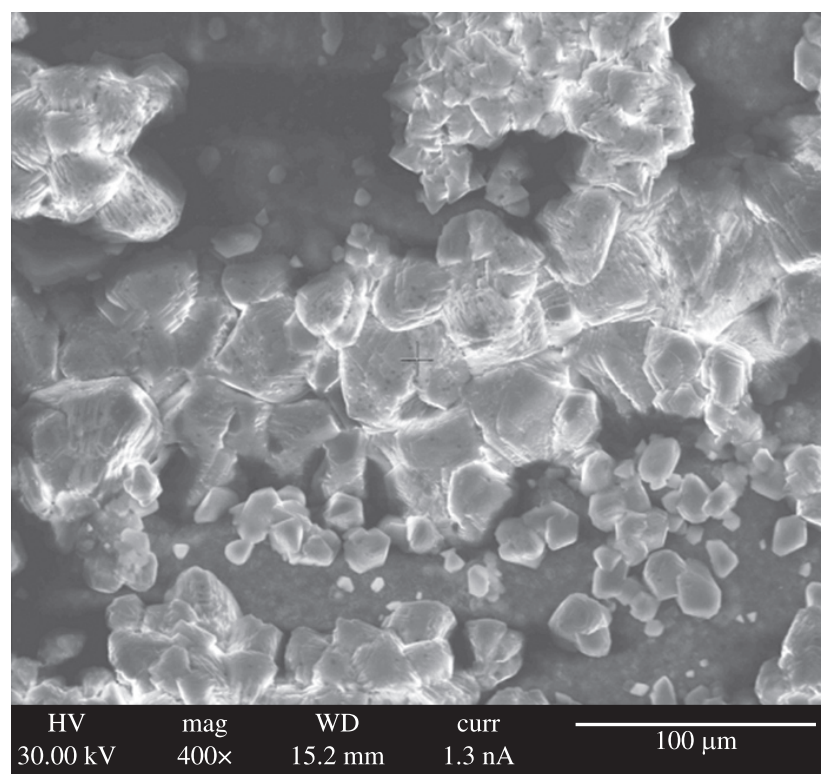

(c)

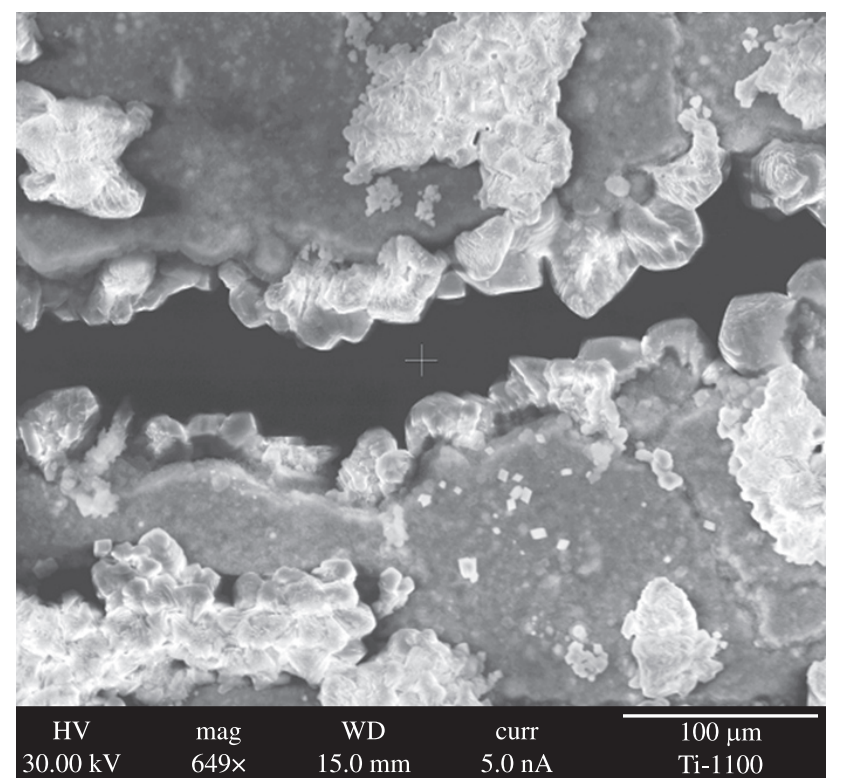

(b)

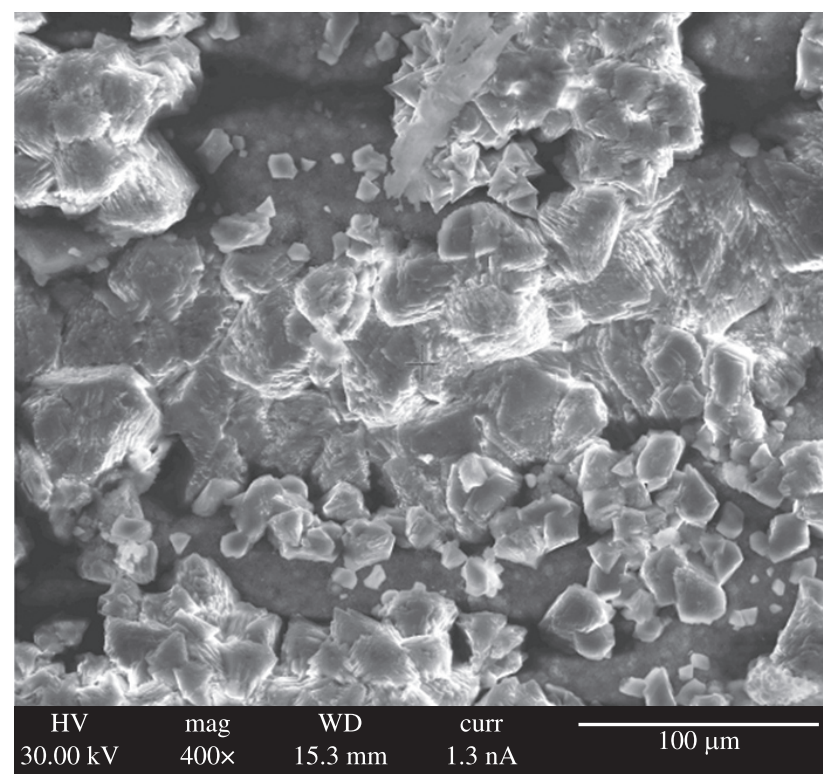

(d)

Figure 6. Self-healing phenomenon of a $100 \mu \mathrm{m}$ width crack in ECC M45. 
of 150000 as a Viscosity Modifying Agent (VMA). SP neutralizes different surface charges of cement particles and thus disperses the aggregates formed by electrostatic attraction. The VMA is a high efficiency, milky white liquid admixture enabling production of self consolidating concrete (SCC) by modifying the rheology of concrete.

SP was used only when the mixer can not mix further (Figure 4c). The liquefied fresh mortar matrix should reach a consistent and uniform state before adding fibers. After examining the mortar matrix and making sure there is no clump in the bottom of the mixer, PVA fibers were slowly added into the mortar matrix and mixed until all fibers were evenly distributed. The fresh mixture was then cast into coupon molds measuring $150 \times 75 \times 13 \mathrm{~mm}$. The fresh ECC specimens were covered with plastic sheets and demolded after 24 hours. After demolding, specimens were air cured at temperature $21 \pm 1{ }^{\circ} \mathrm{C}$ for 2 days. The relative humidity $(\mathrm{RH})$ of the laboratory air is $45 \pm 5 \%$.

\subsection{Specimens under tension}

Coupon specimens were used to conduct uniaxial tensile test by servohydraulic testing system under displacement control mode for each mix at specified tensile deformation $2 \%$ (Figure 5). The loading rate was $0.0025 \mathrm{~mm} / \mathrm{s}$ to simulate a quasi-static loading condition. Aluminum plates were glued on both sides at the ends of coupon specimens to facilitate gripping. Two external linear variable displacement transducers were attached to the specimen with a gauge length of approximately $50 \mathrm{~mm}$ to measure the specimen deformation. When the tensile strain reached the predetermined value, the tensile load was released, and the specimens were removed from the tensile test machine to prepare for predetermined environmental conditioning.

\section{ESEM Microscopy of Self-Healing Phenomenon in ECC}

The self-healed specimens to be observed were $1 \mathrm{~cm}$ cubes cut from the damaged ECC which was loaded to tensile strain of $2 \%$. Environmental Scanning Electron Microscopy (ESEM) capable to image the self-healed specimen continuously was utilized to characterize the self-healing phenomenon. The damaged specimen was placed in water for 24 hours before self-healing phenemenon was imaged in the ESEM. After that, the specimen was allowed to dry for 24 hours and imaged again. This process was repeated over several cycles to monitor the same location in a deliberately chosen crack. Each wet-dry cycle cost 48 hours for the specimen to be immersed in water and dry up in the air.

In the ECC M45 specimen, both a crack with around $100 \mu \mathrm{m}$ width and a single fiber in it were monitored to examine the growth of chemical products in these locations. It was pointed out by $\mathrm{Li}$ and Yang $^{7}$ that recovery magnitude of tensile stiffness, ductility and strength of damaged ECC specimen can be adequate after only 3 wet-dry cycles. It is seen from the self-healing sequence (Figure 6) that the crack of $100 \mu \mathrm{m}$ width were occupied fully with large crystal structure of carbonate after 3 wet-dry cycles.

Hydration of unreacted cement and fly ash also leads to an increased strength of ECC matrix and fiber/matrix interfacial bonding (due to a strong hydrophilic nature of PVA fiber). The increase of matrix cracking strength prevents crack initiating and propagation from defect sites and excessively strong interfacial bonding increases the tendency of fiber rupture. Both mechanisms cause a negative impact on the development of multiple micro-

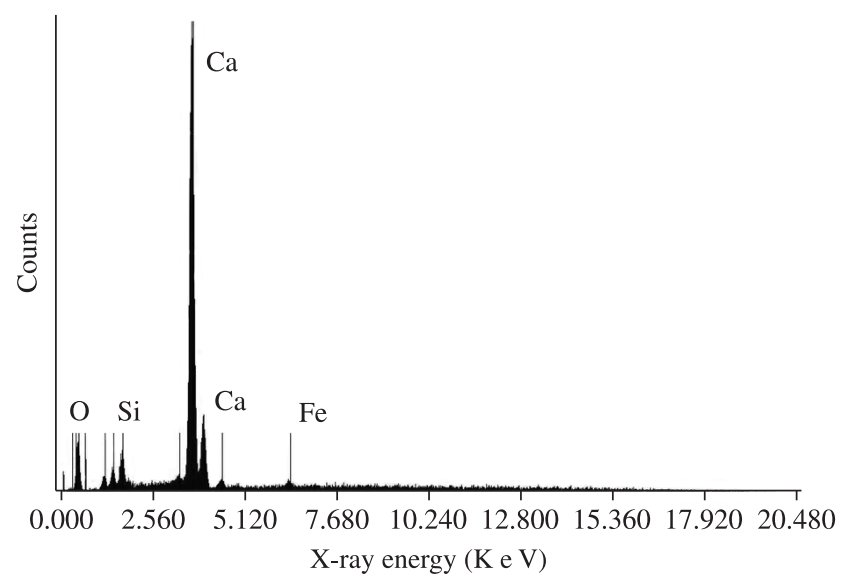

Figure 7. ESEM surface chemical composition analysis (EDX) of self-healed crack formations.

cracking, and therefore lower tensile ductility of ECC is observed as a consequence.

It is shown by surface chemical analysis (EDX) of self-healed ECC specimen that the crystals formed within and on the surface of the cracks are hydrated cement products, primarily composed of calcium carbonate. Calcium is the main elemental composition of the chemical product to complete the self-healing procedure. By conducting EDX quantification for oxides (Figure 7), the amount of calcium carbonate $\left(\mathrm{CaCO}_{3}\right)$ can be estimated by combining equal amount of $\mathrm{CaO}$ and $\mathrm{CO}_{2}$. Interestingly, excessive $\mathrm{CaO}$ was found which implied the existence of calcium hydroxide $(\mathrm{CaOH})_{2}$. Therefore, it is likely that the chemical product at early age of self-healing is a compound of both calcium carbonate (precipitation or crystallization) and calcium hydroxide (further hydration of cement grain).

Measurements were also performed on a self-healed ECC 2.8FA mix design over several wet-dry cycles (Figure 8 ). The average crack width of ECC $2.8 \mathrm{FA}$ is about $10 \mu \mathrm{m}$ with the increase of fly ash amount, greatly reduced from the average crack width $100 \mu \mathrm{m}$ of ECC M45. The rehydration products dominated selfhealing of ECC 2.8FA possesses very different characteristics from ECC M45 which is with less amount of fly ash. This observation suggested that ECC 2.8 FA with more microcracks and smaller crack width will most likely have lower permeability and better durability than ECC M45. Tighter crack width in ECC 2.8FA with larger amount of fly ash is likely to promote better self-healing behavior. The influence of crack width and mix design on self-healing is obvious. The type of self-healing for ECC 2.8FA is more effective for the recovery of mechanical property over ECC M45. Because mechanical properties of the hydration products are more desirable over that of brittle crystal growth. Thus the strength of ECC 2.8FA can be better recovered. Fly ash is usually considered a beneficial ingredient for long term strength development in ECC due to its pozzolanic properties. Since pozzolanic reaction demands high level of $(\mathrm{CaOH})_{2}$, there is less chance for large crystal growth in ECC 2.8FA. This phenomenon is verified in the self-healing phenomenon of ECC 2.8FA where lower amounts of carbonate crystal growth are observed (Figure 8). Therefore, the optimization of fly ash content is important while designing ECC mixes. The cracks widths should remain small so that self-healed chemical products have capability to close the crack during the self-healing process. 


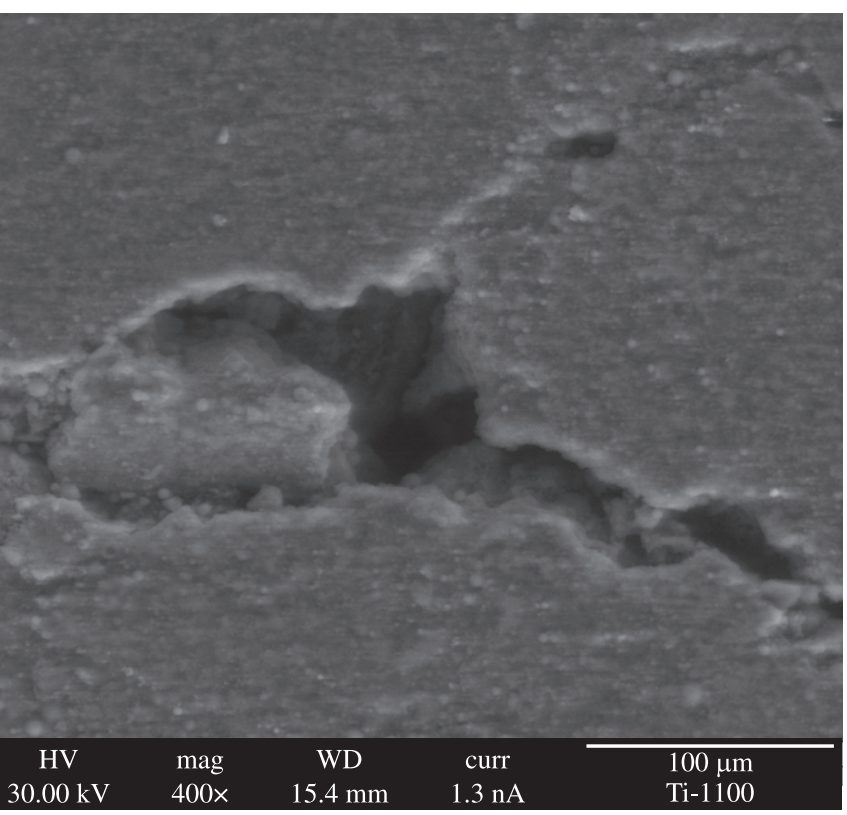

(a)

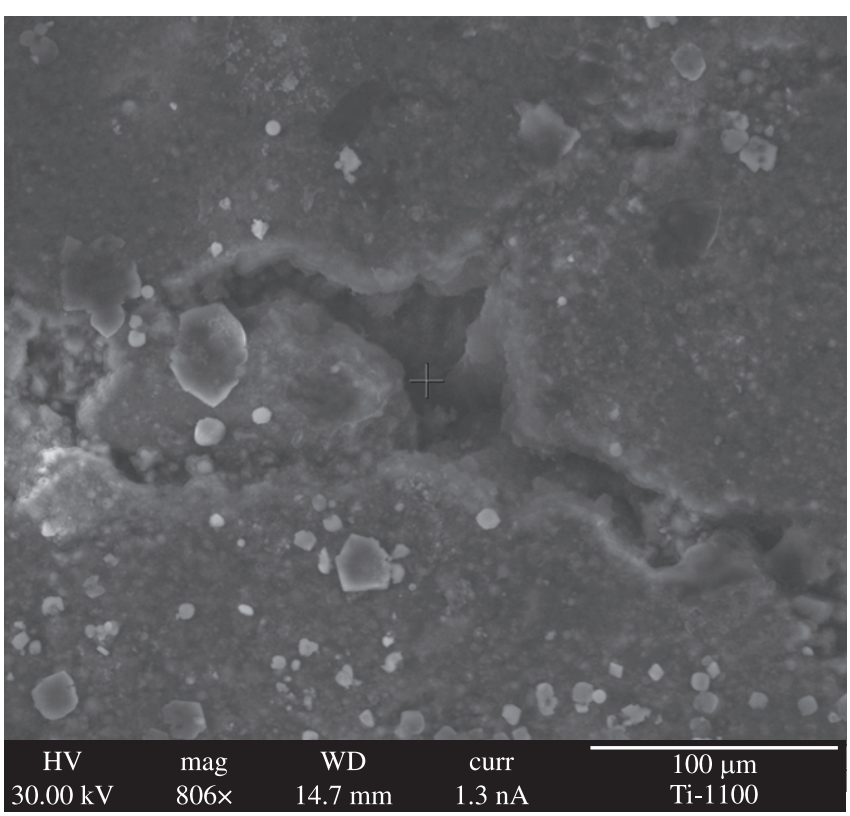

(c)

Figure 8. Self-healing phenomenon of a $10 \mu \mathrm{m}$ width crack in ECC 2.8 FA.

\section{Conclusion}

Self-healing of ECC (Engineered Cementitious Composites) subjected to cyclic wetting and drying regimes is investigated in this paper. The inherent tight crack width less than $100 \mu \mathrm{m}$, make ECC an ideal material to engage in robust self-healing. ECC structures subjected to outdoor environmental conditions such as wind and rain runoff are simulated by acceletated test method of wet-dry cycles. Uniaxial tensile tests of ECC M45 and ECC 2.8FA specimen are conducted respectively. It is found that average crack width of ECC 2.8FA is around $10 \mu \mathrm{m}$ with increased amount of fly ash, while the average crack width of ECC M45 is around $100 \mu \mathrm{m}$. Experimental results completed by ESEM investigations showed that new crystals

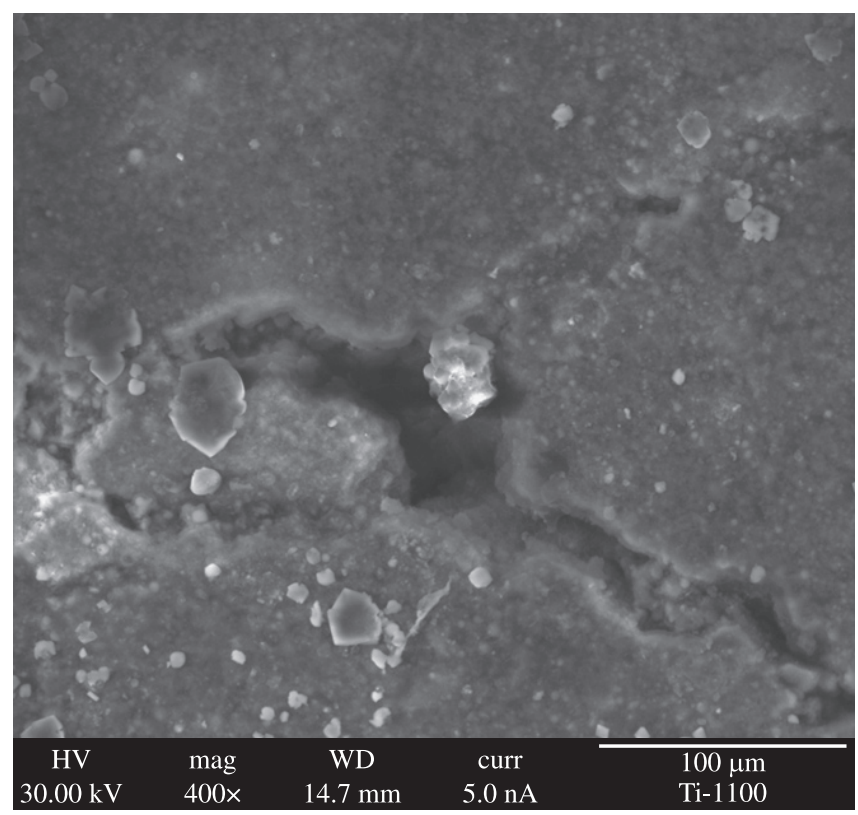

(b)

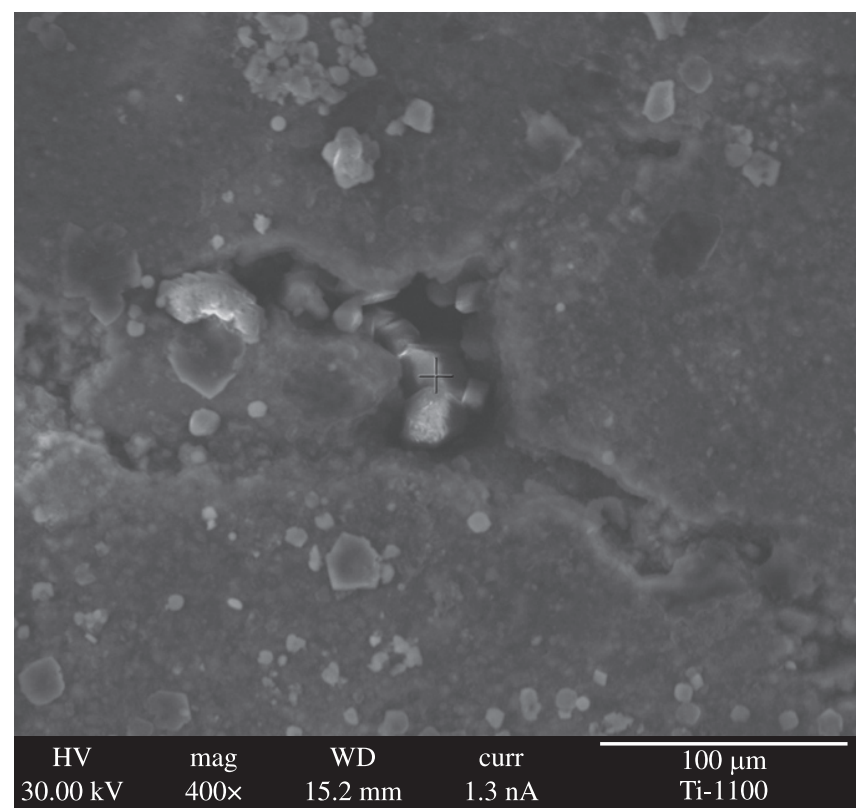

(d)

and hydration product have precipitated in the crack. EDX was also carried out to characterize the chemical components of healing materials. New insights about the microstructure and chemical composition analysis of ECC specimens initially cracked to $2 \%$ strain and then self-healed are provided. The self-healing of ECC $2.8 \mathrm{FA}$ is more effective due to the more desirable mechanical properties of the hydration products over that of brittle crystal growth in ECC M45. It can be expected that self-healing of ECC will greatly benefit the long-term durability and safety of civil infrastructure. Further studies in the field should be conducted to confirm this expectation in actual structures exposed to natural environments and the precise chemical composition of reheal products remains to be explored. 


\section{Acknowledgement}

Financial supports from China Scholarship Council are gratefully acknowledged. This work was completed while the author Yu.J.H was a Visiting Professor at ACE-MRL laboratory under Professor Li.V.C's supervisition in University of Michigan.

\section{References}

1. Yu JH and Li D. Srain rate and interfacial property effects on random fiber cementitious composites. Journal of Strain Anaysis for Engineering Design. 2009; 44(6):417-425.

2. Yu JH and Li VC. Research on Production, Performance and Fibre Dispersion of PVA Engineering Cementitious Composites. Materials Science and Technology. 2009; 25(5):651-656.
3. Yang EH and Li VC. Fiber-bridging Constitutive Law of Engineered Cementitious Composites. Journal of Advanced Concrete Technology. 2008; 6(1):181-193.

4. Li VC and Wang S. Microstructure Variability and Macroscopic Composite Properties of High Performance Fiber Reinforced Cementitious Composites. Probability of Engineering Mechanics. 2006; 21(3):201-206.

5. Yingzi Y, Michael DL, En-Hua Y and Li VC. Autogenous Healing of Engineered Cementitious Composites under Wet-Dry Cycles. Cement and Concrete Research. 2009; 39(5):382-390.

6. Edvardsen, C. Water permeability and autogenous healing of cracks in concrete. ACI Materials Journal. 1999; 96(3):448-455.

7. Li VC and Yang EH. Self-Healing in Concrete Materials. In: Zwaag S (Ed.). Self Healing Material. Dordrecht, The Netherlands: Springer; 2007. p. 161-193. 